\title{
Teacher Retention: Important Considerations for Rural and Urban Districts in Texas
}

\author{
Kara Rosenblatt, Kevin Badgett, James Eldridge \\ The University of Texas Permian Basin \\ USA
}

\begin{abstract}
Keeping quality teachers in schools is paramount to student achievement. Thus, in this study, the authors explore an intersection of research on factors that contribute to why teachers choose to leave a teaching role in urban and rural school districts in Texas. This is an important area for empirical research because the loss of effective teachers has a significant impact on student achievement and since 1989, the national teacher attrition rate in the United States has increased 50\% and remains steady at approximately $8 \%$. Furthermore, in Texas, teachers leave the classroom at more than twice the national average. Findings of a regression analysis highlight the importance of focused support and training for teachers who work with students who are identified as At Risk and/or served by special education in both the rural and urban settings. Findings also illustrated some factors have a different impact on retention of teachers depending on whether the district is in a rural or a major urban setting for both the percentage of a district's employees who are in a school leadership role and for the percentage of a district's teachers in their first five years of service. Implications will be explored.
\end{abstract}

\section{Introduction}

On average, high-quality, experienced teachers are more effective at raising student academic performance [1]. Therefore, keeping quality teachers in schools is paramount to student achievement [2, 3 ,4, 5, 6, 7]. Unfortunately, since 1989, the average attrition rate for teachers in the United States has increased by $50 \%$ and remains steady at approximately $8 \%$ [7]. The percentage of teachers leaving the classroom in Texas is more than twice that rate at $16.6 \%$ for $2014-2015$ [8]

There is a myriad of factors that contribute to whether or not teachers choose to stay at or leave a school. Previous research has found those reasons include organizational and policy issues as well as personal issues [9, 10]. More specifically, prior research has demonstrated factors that influence a teacher's decision to stay or go include but are not limited to perceived support from administrators [11], a lack of effective training particularly for new special educators [12,13], student behavior [11], and salaries [14].
As already referenced, teacher retention in Texas has been an even greater challenge. In a recent report titled Understanding Teacher Shortages, a State-byState Analysis of Factors Influencing Teacher Supply, Demand, and Equity [15, 16] the Learning Policy Institute assigned Texas a score of 1.88 on a five-point scale. This score indicates Texas, as a whole, is less supportive of teacher recruitment and retention than other states in the United States. Moreover, the Learning Policy Institute also found that Texas teachers leave the profession at twice the national rate and that teachers plan to leave the profession at a rate that is more than twice the national average.

Realizing this urgency and in order to more fully explore the impact of factors previously shown to contribute to teacher retention in Texas, Moore, Rosenblatt, Badgett, and Eldridge [17] looked at teacher retention in Texas Urban district (published) and Rosenblatt, Badgett, and Eldridge looked at teacher retention in rural districts (in review). In doing so, the authors accessed and downloaded data files that contained publicly available information published in Texas Academic Performance Reports (TAPR). Among other factors, these studies considered the impact of teacher salary, experience, administrative support (in the form of the percentage of administrators in a district), district funding, behavioral placement for students, and percentages of students identified as ELL and At Risk and served by special education on the teacher turnover rate. Though each of these studies focused on a different district type (urban and rural), findings for each distinct district type revealed similar areas of concern. The purpose of this research is to explore that intersection and to highlight important considerations and implications for both the similarities and the differences.

\section{Methodology}

\subsection{Sample}

During the 2014-2015 school year, there were more than 5.2 million students in Texas school districts with over 342,000 teachers employed in 8,500 schools. These schools were part of more than 1,200 schools' districts and open-enrollment charter schools across the state during that school year [8]. Of those more than 1,200 districts, 453 were 
categorized as Rural District Types and 11 were categorized as Major Urban District Types. Districtlevel TAPR documents were used in the earlier analyses. In order to arrive at a better understanding of factors which contribute to teacher retention in rural and urban districts in Texas, district level data were analyzed for each of those districts.

\subsection{Research Design}

The studies used a non-experimental, retrospective research design. This was an appropriate design since the data were preexisting and could not be changed or influenced in any manner [18]. The primary purpose for the analysis of data collected in these studies was to identify specific factors that impact teacher retention within those district types in Texas. In order to explore this impact, the researchers identified significant factors that influence teacher retention previously reported in published literature.

\subsection{Operational Definitions}

For the purpose of establishing an understanding of key vocabulary, several terms were operationally defined. Teacher retention was defined as the inverse of the rate of teacher turn-over found in Texas Academic Performance Reports (TAPR) for districts in the state of Texas. Data for these studies included only those districts identified as part of the "Rural" or "Major Urban" district types in Texas. Having identified factors which researchers validated through previously published research as having a significant impact on teacher retention, there were several important variables which were explored in these studies. Those variables included the administrative support, teacher salary, student behavior, and new teacher experience, student race and ethnicity, staff race and ethnicity, percentage of student population identified as English Language Learners, and socio-economic status of the student population. Other variables that might impact or confound the variables listed above included student participation rate in special education, district funding, and percentage of students identified as At Risk

Including the variables described above, the following terms were defined as follows:

1) District Special Education Participation Percentage - Percent of a district's students served in Special Education

2) Teacher Tenure Average - The average years of experience for teachers in a district

3) New Teachers- Percentage of a district's teaching faculty within their first 5 years of experience
4) Administrative Support - Percentage of a district's staff classified as Campus Administration

5) Percentage of Students Identified as At Risk Percentages of students identified in the TAPR as At Risk.

6) District Funding - General funds total operating revenue

7) Teacher Salary - Average salary for the district's teachers

8) Race/Ethnicity - Race and Ethnicity was defined categorically as Asian/Pacific Islander, Native American, African American, Hispanic, and White. This is consistent with TAPR reporting.

9) Student Behavior - Percentages of students reported in the TAPR as having disciplinary placements in 2013-2014.

10)English Language Learners - Students identified as LEP are defined in section 29.052 of the Texas Education Code (TEC) as "a student whose primary language is other than English and whose English skills are such that the student has difficulty performing ordinary classwork in English" (para. 1). This was the definition for this research. Percentages of LEP students in a given district was based on those reported in the TAPR report.

11) Socio-Economic Status - Percentages of students identified in the TAPR as "Economically Disadvantaged."

\section{Research Procedures/Data Collection}

All data necessary for these studies were publicly available and were found in district-level TAPR reports or from the TEA's data sort program. Since these studies utilized archival data previously collected, informed consent was not required. However, though these studies were IRB exempt, an IRB application was submitted and approved. All information pertinent to the data analysis was loaded into an Excel spreadsheet and imported into SPSS Version 22 for analysis.

\subsection{Data Analysis}

All data collected for these studies were from the 2014-2015 TAPR district-level reports. Data were analyzed using backward multiple regression techniques as found in the SPSS software. The backward multiple regression technique removes insignificant variables at each stage of the analysis to develop the most efficient regression equation using only those variables that are significant. Significance for the models was set at $\mathrm{p}<.05$. 


\section{Findings}

\subsection{Urban Findings}

As illustrated in Table 1, the regression identified four factors as significantly impacting a teacher's decision to stay at or leave a teaching position at a school in the urban setting. Those factors included the percentage of students at the campus who are served by Special Education, the average teacher tenure at the campus, the percentage of teachers serving in their first five years, and the percentage of students identified as At Risk (of dropping out of school). Two of those factors (percentage of students served by Special Education and the percentage of students identified as At Risk) were revealed to have a positive relationship with the dependent variable and two were shown to have a negative relationship (average teacher tenure and percentage of teachers in their first five years of experience). In summary, this means that as the percentage of students identified as At Risk and those served by Special Education increase, teachers are more likely to leave. It also means that as the average tenure of a teaching staff increases, teachers are more likely to stay in a teaching role at that campus.

Table 1. Teacher Retention in Texas Urban Districts Beta Values and Correlational Information on Significant Factors*

\begin{tabular}{lllll}
\hline \multirow{2}{*}{ Model } & \multicolumn{2}{l}{$\begin{array}{l}\text { Unstandardized } \\
\text { Coefficients }\end{array}$} & $\begin{array}{l}\text { Standardized } \\
\text { Coefficients }\end{array}$ & $\mathrm{t}$ \\
\cline { 2 - 5 } & $\mathrm{B}$ & $\begin{array}{l}\text { Std. } \\
\text { Error }\end{array}$ & Beta & \\
\hline 5 & -40.195 & 20.960 & & -1.918 \\
(Constant) & & & & \\
SPED $^{*}$ & -2.521 & .975 & -.757 & -2.587 \\
TENAVE $^{* *}$ & 5.977 & 2.763 & 1.419 & 2.163 \\
FIRST5 $^{* *}$ & 1.961 & .589 & 2.507 & 3.331 \\
ATRISK $^{*}$ & -.668 & .274 & -1.681 & -2.435 \\
${ }^{*} \mathrm{p} \leq 0.05,{ }^{* *} \mathrm{p}=0.000$ & & &
\end{tabular}

Interestingly, though the impact is very small, it also means that as the percentage of teachers in their first five years of teaching increases, teachers are also more likely to stay.

\subsection{Rural Findings}

Findings for the rural district type, shown in Table 2, revealed some similarities and some differences. As illustrated in Table 2, whereas the regression found four significant factors for urban type districts in Texas, the subsequent regression analysis identified five factors as significantly impacting a teacher's decision to stay at or leave a teaching position at a school in a rural district type in Texas.

Table 2. Teacher Retention in Texas Rural Districts Beta Values and Correlational Information on Significant Factors*

\begin{tabular}{lllll}
\hline & \multicolumn{2}{l}{$\begin{array}{l}\text { Unstandardized } \\
\text { Coefficients }\end{array}$} & $\begin{array}{l}\text { Standardized } \\
\text { Coefficients }\end{array}$ & $\mathrm{t}$ \\
\cline { 2 - 5 } & $\mathrm{B}$ & $\begin{array}{l}\text { Std. } \\
\text { Error }\end{array}$ & Beta & \\
\hline $\begin{array}{l}5 \\
\text { (Constant) }\end{array}$ & 15.820 & 3.235 & & 4.891 \\
SPED* $^{*}$ & 0.280 & 0.130 & 0.082 & 2.157 \\
TENAVE** $^{*}$ & -1.543 & 0.236 & -0.303 & -6.547 \\
FIRST5 $^{* *}$ & 0.258 & 0.039 & 0.306 & 6.641 \\
ADMIN $^{*}$ & 0.717 & 0.283 & 0.096 & 2.531 \\
ATRISK* $^{*} 0.100$ & 0.030 & 0.128 & 3.332 \\
\hline${ }^{*} \mathrm{p} \leq 0.05,{ }^{* *} \mathrm{p}=0.000$ & &
\end{tabular}

Those factors included the percentage of students at the campus who are served by Special Education, the average teacher tenure at the campus, the percentage of teachers serving in their first five years, the percentage of a district's employees coded as Campus Administration, and the percentage of students identified as At Risk. Four of those factors (percentage of students served by Special Education and the percentage of students identified as At Risk, percentage of teachers in their first five years of experience, and the percentage of a district's employees coded as Campus Administration) were revealed to have a positive relationship with the dependent variable and one was shown to have a negative relationship (average teacher tenure). In summary, this means that as the percentage of students identified as At Risk and those served by Special Education increase in a rural district type in Texas, teachers are more likely to leave. Similarly, as the percentage of teachers serving in their first five years and the percentage of a district's employees coded as Campus Administration increases in the rural setting in Texas, teachers are more likely to leave their teaching role at the campus. It also means that as the average tenure of a teaching staff increases in this district type in Texas, teachers are more likely to stay in a teaching role at that campus. Notably, it is interesting that the percentage of teachers in their first five years is significant but has a different impact in the rural setting compared to the urban setting in Texas. Also, while an increase in the percentage of a district's staff in a Campus Leadership role negatively impacts teacher retention in the rural setting, it was not found to significantly 
impact teacher decisions about staying or leaving in the urban setting.

Summarily, in both the rural and urban settings, the factors found to significantly contribute to teacher attrition include the percentage of students served by Special Education, the percentage of students identified as At Risk, the percentage of teachers in their first five years of service, and the average amount of experience for a teaching staff. The factor found to significantly contribute to attrition in rural districts that did not emerge in the regression analysis for urban districts was the percentage of a district's professional staff serving in a campus administrative role.

\section{Implications}

The intersection of these two different studies offers interesting implications for preparation programs, practitioners, and policy makers. Preparation programs serve candidates who aspire to serve in a wide variety of educational settings. Preparation program learning objectives that address how contextual and situational factors influence a teacher's experience can support the accomplishment of a variety of goals including but not limited to cultivating realistic expectations about their earlycareer experiences, an ability to more effectively diagnose their own experiences and reflections in a metacognitive way, and can offer aspiring educators a key lens that will support their ability to select a best employment fit for them. Furthermore, given the rise of online education, educator preparation programs are increasingly working with students in diverse settings [19]. Standardizing an approach that includes an exploration of how different factors impact teachers in different settings is a reasonable area for curricular focus.

This intersection is also instructive for practitioners, particularly those in leadership positions. Given constants like the impact on teacher decisions to leave a role when student populations served have more complex educational needs should reinforce the importance of training and support for recognizing and addressing those student needs. This research also reinforces the intuitive observation that school systems in different settings are different and may have different needs. Whereas this research demonstrates that the percentage of teachers in their first five years of experience is a positive factor in urban schools, it does not show why that is the case. Taking a closer look at what urban districts are doing to support early-career teachers could offer new strategies and knowledge to districts in the rural setting. District-level leaders in the rural setting may want to give more attention to staffing formula decisions related to school leadership positions. As this factor does not appear to have the same negative impact on faculty retention in the urban setting, some consultation with urban district leaders around staffing formulas and decisions for campus leadership.

Finally, this research can inform the need to take a differential approach to recruitment and retention of teachers in different settings particularly when a region, state, or other government entity oversees operations of schools in vastly different settings. Such an approach may have implications for policy related to training, funding, and accountability.

\subsection{Implications for Future Research and Conclusion}

Because this research is thoroughly quantitative and relied on regression analyses, the authors can offer empirically based considerations for policy and practice; however, while this research addresses what is happening in these settings, it cannot fully address why this is happened. Future qualitative research that explores the perceptions and perspectives of educators in schools in these settings could shed light on why these factors influence teacher retention in the way they do.

This research is valuable because it can inform important areas of focus that, if addressed, may have a mitigating impact on teacher attrition and, consequently, have a positive impact on the need to dedicate resources to the costly process of recruitment. This research is also important because it reinforces the rational observation that educators in different settings will have different needs. Careful attention to contextual characteristics may inform a more generalized approach to meeting needs that are characteristic of distinct district types and may, ironically, support a more coordinated and systemic approach to meeting the needs of all students within a broader system like the state of Texas.

\section{References}

[1] Hanushek, E., Kain, J. F., \& Rivkin, S. G. (2004) 'Why public schools lose teachers.' The Journal of Human Resources, 39(2), pp. 326-354.

[2] Berry, A.B. (2012) 'The relationship of perceived support to satisfaction and commitment for special education teachers in rural areas.' Rural Special Education Quarterly, 31(1), pp. 3-14.

[3] Kaden, U., Patterson, P.P., Healy, J., \& Adams, B.L. (2016) 'Stemming the revolving door: Teacher retention and attrition in arctic Alaska schools.' Global Education Review, 3(1), pp. 129-147.

[4] Darling-Hammond, L. (2010) 'Teacher education and the American future.' Journal of Teacher Education, 61(1-2), pp. 35-47. 
[5] Ingersoll, R. M. (2001) 'Teacher turnover and teacher shortages: An organizational analysis.' American Educational Research Journal, 38, pp. 499534.

[6] Ingersoll, R.M., \& May, H. (2011) 'Recruitment, retention, and the minority shortage.' Philadelphia, PA: Consortium for Policy Research in Education, University of Pennsylvania. DOI: 10.12698/cpre.rr69

[7] Ingersoll, RM., Merrill, L., \& Stuckey, D. (2014). 'Seven trends: The transformation of the teaching force, updated April 2014.' CPRE Report (\#RR-80). Philadelphia, PA: Consortium for Policy Research in Education, University of Pennsylvania.

[8] Texas Education Agency. (2015) "Overview of Texas schools." Retrieved from http://tea.texas.gov/ districtinfo.aspx

[9] Barth, P., Dillon, N., Hull, J., \& Holland Higgins, B. (2016) 'The teacher pipeline: An overview of teacher shortages.' Alexandria, V.A.: Center for Public Education.

[10] Sutcher, L., Darling-Hammond, L., \& CarverThomas, D. (2016) 'A coming crisis in teaching? Teacher supply, demand, and shortages in the U.S.' Palo Alta, CA: Learning Policy Institute.

[11] U.S. Department of Education, National Center for Education Statistics. (2010) 'Teacher attrition and mobility: Results from the $2008-09$ Teacher Follow-up Survey' (NCES 2010 - 353). Washington, DC: Author. Retrieved from http://nces.ed.gov/fastfacts/display.asp?id=28.

[12] Helms-Lorenz, M., Slof, B., Vermue, C. E., \& Canrinus, E. T. (2012). Beginning teachers' selfefficacy and stress and the supposed effects of induction arrangements. Educational Studies, 38(2), 189-207.

[13] Pedota, P. J. (2015). How Can Student Success Support Teacher Self-Efficacy and Retention? Clearing House, 88(2), 54-61. doi:10.1080/00098655.2014.998600

[14] Consortium for Policy Research in, E. (2009) 'Taking Human Capital Seriously: Talented Teachers in Every Classroom, Talented Principals in Every School. Principals and Recommendations for Strategic Management of Human Capital in Public Education.'

[15] Learning Policy Institute. (2016) 'Understanding teacher shortages: A state-by-state analysis of the factors influencing teacher supply, demand, and equity.' Palo Alto, CA: Author.

[16] Learning Policy Institute. (2018) 'Understanding teacher shortages: 2018 update: A state-by-state analysis of the factors influencing teacher supply, demand, and equity.' Palo Alto, CA: Author.

[17] Moore, L., Rosenblatt, K., Badgett, K., \& Eldridge, J. (2018) 'Urban Texas teacher retention: Unbelievable empirical factors tied to urban teacher persistence and retention.' Literacy Information and Computer Education Journal, 9(2), pp. 2923-2931.

[18] Chatterji, M. (2007) 'Grades of evidence: Variability in quality of findings in effectiveness studies of complex field interventions.' American Journal of Evaluation, 28(3), pp. 239-255. doi: $10.1177 / 1098214007304884$

[19] Carver-Thomas, D. (2018) 'Diversifying the teaching profession: How to recruit and retain teachers of color.' Palo Alto, CA: Learning Policy Institute. 